\title{
The Effect of Learning Engagement on Learning Burnout of College Students
}

-- Taking Academic Self-efficacy as a Mediating Variable

\author{
Shuguang Yan \\ China Agricultural University Yantai Institute, Yantai, China \\ yqh@cau.edu.cn
}

\begin{abstract}
To explore the status quo of learning engagement and learning burnout, the mechanism of learning engagement on learning burnout, and the mechanism of academic Self-efficacy. Methods:A total of 309 college students were randomly selected as research samples. The samples were investigated by using the College Students' learning engagement Scale, learning burnout scale and academic Self-efficacy questionnaire, and the results were analyzed by using SPSS26.0 and macro program Process. (1) there were significant differences in academic engagement between male and female, urban and rural, class position and political status, and there were significant differences in learning burnout between urban and rural and political status. (2) Learning engagement and academic Self-efficacy had negative predictive effects on learning burnout. (3) Academic Self-efficacy plays a partially mediating role in the relationship between learning engagement and learning burnout. This study introduces academic Self-efficacy into the influence of learning input on learning burnout, constructs a mechanism model of the influence of learning input on learning burnout, and carries out empirical tests on this model, which is the improvement and expansion of related research fields.
\end{abstract}

Keywords: Learning Engagement; Learning Burnout; Academic Self-efficacy; College Students.

\section{Introduction}

China's Education Modernization 2035, issued by the CPC Central Committee and The State Council, states,"By 2035, China will achieve overall education modernization, enter the ranks of education power, and promote China to become a country of learning, human resources and talent power."(policy from Ministry of Education of the People's Republic of China.) Some scholars point out that study is the main task of college students and an important part of college life.[1] In general, policy circles and academic circles pay more and more attention to the learning development of college students. According to statistics released by the Ministry of Education, by 2020, there will be 41.83 million college students in China, accounting for 28 percent of the country's total population. (Data are from the Development and Planning Department of the Ministry of Education.) These college students are the main force of the strategy of developing China into a country of talents and modernization, and their learning has a certain predictive effect on the quality of talents in the future. Therefore, it is necessary to conduct in-depth research on the learning of college students to provide empirical support for improving the comprehensive quality of talents in the future.

\subsection{The Relationship between Learning Engagement and Learning Burnout}

Learning engagement refers to a continuous and substantial positive psychological state of learners in learning, including three dimensions of vitality, dedication and concentration. [2,3] Learning engagement is an important index to measure learners' efforts. [4] The study burnout of college students is the negative attitude and behavior of being tired of study due to the pressure of study or lack of interest in study.[5,6] There is a close relationship between learning burnout and learning engagement, [7-9] Shen and other scholars proposed that learning engagement is negatively correlated with learning burnout.[7] Duan and other scholars pointed out that learning burnout has a good predictive ability for learning engagement. [8,9] In view of this, hypothesis H1 is proposed: learning engagement is negatively correlated with learning burnout. 
Volume 3 (2021)

Studies have shown that learning engagement and learning burnout are affected by gender, urban and rural areas and class position. [4,7,8] In addition, the study of Bi Juan et al. found that there is a certain difference in the performance of party members and non-party members in learning [10] Therefore, hypothesis $\mathrm{H} 2$ is proposed: there are significant differences between learning engagement and learning burnout in gender, urban and rural areas, class position, political status and other demographic variables.

\subsection{The Mediating Effect of Academic Self-efficacy}

Academic Self-efficacy is an individual's subjective judgment of whether he has the ability to achieve a certain learning goal in learning activities.[11] Some foreign scholars have mentioned that learning engagement is related to Self-efficacy.[12]Wilmar further explained and pointed out that more learning involvement has a certain positive predictive effect on high Self-efficacy. Low Selfefficacy will lead to negative learning psychology such as learning burnout.[13]A large number of studies have shown that academic Self-efficacy is negatively correlated with learning burnout, which can be used as a predictor of learning burnout. The higher the level of academic Self-efficacy, the lower the level of learning burnout, and vice versa.[14-16]Other studies have found that the higher the degree of learning engagement, the lower the level of learning burnout.[17-19]However, the effect of learning engagement on academic Self-efficacy needs to be further enriched and expanded. Based on some theoretical research and practical observations,[20]This paper speculates that academic Selfefficacy plays a mediating role in the relationship between college students' learning engagement and learning burnout, and proposes hypothesis H3: academic Self-efficacy can transfer the impact of learning engagement on learning burnout and act as a bridge.

To sum up, most previous studies have explored learning engagement, academic Self-efficacy and learning burnout from a single perspective, and there are few comprehensive studies on the impact path of learning engagement on learning burnout. From a comprehensive perspective, this paper introduces the mediating variable of academic Self-efficacy, constructs a research model of learning engagement and learning burnout in the context of university, and explores the internal mechanism among the three variables of learning engagement, academic Self-efficacy and learning burnout. This paper aims to provide theoretical support for future intervention research on learning burnout and provide reference for reducing the level of learning burnout of college students.

\section{Subjects and Methods}

\subsection{Characteristics of Subjects}

A total of 309 questionnaires were sent out, 309 were returned and 290 were valid, with effective recovery of $93.9 \%$. Basic information of subjects is shown in Table 1.

\subsection{Survey Tools}

\subsubsection{Learning Engagement Scale}

With reference to Li, etc. [21] The revised college Students' learning engagement Scale contains 17 questions, which are divided into three dimensions: motivation, energy and concentration. The 7point Likert scoring method is adopted. The higher the score is, the higher the level of learning engagement is. In this study, the standardized clone Bach $\alpha$ coefficient of the scale was 0.94.

\subsubsection{Academic Self-efficacy Scale}

Borrowed by Joseph Leung [22] The college students' academic Self-efficacy scale was developed, which was divided into two dimensions, learning ability Self-efficacy and learning behavior Selfefficacy. Each dimension had 11 questions, a total of 22 questions. Likert 5-point scoring method was adopted, and the higher the score, the higher the academic Self-efficacy. In this study, the standardized clone Bach $\alpha$ coefficient of the scale was 0.84 . 
Table 1. Crossover Analysis of Main Characteristics of Demographic Variables

\begin{tabular}{|c|c|c|c|}
\hline \multirow{2}{*}{ Demographic variable } & \multicolumn{2}{|c|}{ gender } & \multirow{2}{*}{ Total (290) } \\
\cline { 2 - 3 } Major & Male (135). & Female (155). & \multirow{2}{*}{} \\
\hline The liberal arts & & & \\
\hline skill & $52(38.5 \%)$. & $101(65.2 \%)$ & $153(52.8 \%)$ \\
\hline In science and engineering & $69(51.1 \%)$ & $39(25.2 \%)$. & $108(37.2 \%)$ \\
\hline Scores ranking & $14(10.3 \%)$. & $15(9.7 \%)$. & $29(10.0 \%)$. \\
\hline Bottom 20\% & & & \\
\hline Top 40\% $~ 60 \%$ & $11(8.1 \%)$. & $5(3.2 \%)$ & $16(5.5 \%)$. \\
\hline Top 20\% 40\% & $15(11.1 \%)$. & $18(11.6 \%)$. & $33(11.4 \%)$. \\
\hline The top 20\%, grade & $33(24.4 \%)$. & $33(21.3 \%)$. & $66(22.8 \%)$ \\
\hline Family location & $32(23.7 \%)$. & $38(24.5 \%)$. & $70(24.1 \%)$ \\
\hline rural & $44(32.6 \%)$. & $61(39.4 \%)$ & $105(36.2 \%)$ \\
\hline Cities and towns & & & \\
\hline The one-child & $68(50.4 \%)$ & $30(19.4 \%)$ & $98(33.8 \%)$ \\
\hline Not the only child & $67(49.6 \%)$ & $125(80.6 \%)$ & $192(66.2 \%)$ \\
\hline Class leader experience & & & \\
\hline The class have been & $70(51.9 \%)$ & $78(50.3 \%)$ & $148(51 \%)$ \\
\hline The class haven't been & $65(48.1 \%)$ & $77(49.7 \%)$ & $142(49 \%)$ \\
\hline Ther & & & \\
\hline The Chinese communist party member & $52(38.5 \%)$. & $55(35.5 \%)$. & $107(36.9 \%)$ \\
\hline NON-CPC member & $83(61.5 \%)$ & $100(64.5 \%)$ & $183(63.1 \%)$ \\
\hline & & & \\
\hline
\end{tabular}

\subsubsection{Learning Burnout Scale}

According to Lian Rong et al[23]The college students' learning burnout scale was developed, including 20 questions, which were divided into three dimensions: depressed mood, inappropriate behavior and low sense of achievement. Five-point Likert scoring method was adopted, and reverse scoring method was used. The higher the score was, the higher the learning burnout level was. In this study, the standardized clone Bach $\alpha$ coefficient of the scale was 0.85 .

\subsection{Analysis Tools}

Using statistical analysis software SPSS26.0 and macro program Process, this paper explores the relationship among college students' learning engagement, academic Self-efficacy and learning burnout through reliability and validity test, descriptive statistics, independent sample T test, oneway analysis of variance, correlation analysis, step-by-step regression analysis and mediating effect test.

\section{Result Analysis}

\subsection{Reliability and Validity Test and Common Method Deviation Test}

On the questionnaire analysis, the reliability of the 59 scoring problem is standardized cloning Bach alpha coefficient is 0.88 , said overall questionnaire has good reliability, through the method of factor analysis to the questionnaire validity test, test data shown in table 2 , the result shows that the questionnaire of KMO test coefficient is 0.95 , suitable for factor analysis, All the extracted information content was above $50 \%$, and the sum of the extracted load squares obtained by factor analysis was above 50\%, indicating that the questionnaire had good validity. Among them, the first 
common factor explains $39.65 \%$ variation, lower than the critical standard of $40 \%$, indicating that there is no serious common method bias in this questionnaire.

Table 2. Factor analysis of questionnaire

\begin{tabular}{|c|c|c|}
\hline \multicolumn{2}{|c|}{ KMO and Bartlett tests } \\
\hline KMO sampling suitability quantity. & The approximate chi-square & 11898.89 \\
\hline Bartlett sphericity test & Degrees of freedom & 1711.00 \\
\hline & significant & 0.00 \\
\hline
\end{tabular}

\subsection{Significant Difference Test}

\subsubsection{Independent Sample T Test}

This study tested the differences of college students' learning engagement and learning burnout in different demographic characteristics by means of independent sample $\mathrm{T}$ test and analysis of variance. The results are shown in Table 3, Table 4 and Table 5. The results show that there are differences in learning engagement and burnout among college students in gender, family location, grade ranking, class position and political status.

Table 3. Difference Test of College Students' Learning Input in Gender, Family Location, Class Position and Political Status $(\mathrm{M} \pm \mathrm{SD})$

\begin{tabular}{|c|c|c|c|c|c|}
\hline & & motivation & energy & focus & $\begin{array}{c}\text { Total learning } \\
\text { engagement }\end{array}$ \\
\hline \multirow{4}{*}{ gender } & $\begin{array}{l}\text { male } \\
(135)\end{array}$ & $\begin{array}{l}30.70+/- \\
6.50\end{array}$ & $\begin{array}{l}27.66+/- \\
7.41\end{array}$ & $\begin{array}{l}23.44+/- \\
5.89\end{array}$ & $81.80+/-18.95$ \\
\hline & $\begin{array}{c}\text { female } \\
(155)\end{array}$ & $\begin{array}{l}29.71+/- \\
5.56\end{array}$ & $\begin{array}{l}25.20+/- \\
5.98\end{array}$ & $\begin{array}{c}21.90+/- \\
4.83\end{array}$ & $76.81+/-15.37$ \\
\hline & $t$ & 1.38 & 3.09 & 2.41 & 2.44 \\
\hline & sig & 0.17 & 0.00 & 0.02 & 0.02 \\
\hline \multirow{4}{*}{ Home place } & $\begin{array}{c}\text { rural } \\
(98)\end{array}$ & $\begin{array}{l}29.02+/- \\
5.42 \\
\end{array}$ & $\begin{array}{l}25.22+/- \\
6.06\end{array}$ & $\begin{array}{c}21.90+/- \\
4.90\end{array}$ & $74.14+/-15.37$ \\
\hline & $\begin{array}{l}\text { Cities and towns } \\
\text { (192) }\end{array}$ & $\begin{array}{l}30.76+/- \\
\quad 6.24\end{array}$ & $\begin{array}{l}26.92+/- \\
7.04\end{array}$ & $\begin{array}{l}22.99+/- \\
5.61\end{array}$ & $80.67+/-18.03$ \\
\hline & $t$ & 2.45 & 2.03 & 1.63 & 2.23 \\
\hline & sig & 0.02 & 0.04 & 0.10 & 0.03 \\
\hline \multirow{4}{*}{ Class position } & $\begin{array}{l}\text { The class cadre } \\
\text { (107) }\end{array}$ & $\begin{array}{l}31.27+/- \\
5.67 \\
\end{array}$ & $\begin{array}{l}27.50+/- \\
6.54\end{array}$ & $\begin{array}{l}23.36+/- \\
5.22\end{array}$ & $82.13+/-16.42$ \\
\hline & $\begin{array}{c}\text { Not The class cadre } \\
(183)\end{array}$ & $\begin{array}{l}29.53+/- \\
6.15 \\
\end{array}$ & $\begin{array}{c}25.68+/- \\
6.86 \\
\end{array}$ & $\begin{array}{l}22.19+/- \\
5.47\end{array}$ & $77.39+/-17.57$ \\
\hline & $t$ & 2.40 & 2.21 & 1.80 & 2.27 \\
\hline & sig & 0.01 & 0.03 & 0.07 & 0.02 \\
\hline \multirow{4}{*}{$\begin{array}{l}\text { Political } \\
\text { landscape }\end{array}$} & $\begin{array}{l}\text { The Chinese communist } \\
\text { party member } \\
(67)\end{array}$ & $\begin{array}{l}32.09+/- \\
5.72\end{array}$ & $\begin{array}{l}28.91+/- \\
\quad 6.69\end{array}$ & $\begin{array}{l}24.28+/- \\
\quad 5.53\end{array}$ & $85.28+/-16.92$ \\
\hline & Non-CPC Members (223) & $\begin{array}{l}29.60+/- \\
6.00\end{array}$ & $\begin{array}{l}25.58+/- \\
6.64\end{array}$ & $\begin{array}{l}22.12+/- \\
5.27\end{array}$ & $77.29+/-16.70$ \\
\hline & $t$ & 3.01 & 3.60 & 2.91 & 3.38 \\
\hline & sig & 0.00 & 0.00 & 0.00 & 0.00 \\
\hline
\end{tabular}

In terms of gender, boys scored significantly higher in energy, concentration and total study involvement than girls. At home, college students from rural areas score significantly lower in the three dimensions of motivation, energy, and total learning investment than college students from cities and towns. In class positions, college students who serve as class leaders in the class are in motivation, energy, and focus. The total scores on the four dimensions of total learning investment 
are significantly higher than those of college students who are not class leaders. In terms of politics, the $\mathrm{p}$-value of each dimension meets the condition of $\mathrm{p}<0.05$, and there is a statistical significance in the dimension of learning investment. Significant difference $(p<0.01)$, All dimensions meet the $p$ value of $\mathrm{p}<0.05$, which exists in the study in this dimension statistical sense of the significant differences $(p<0.01)$, indicating that commitment and learning burnout in the political landscape has better statistical significance on the individual characteristic variables, study into some party members among college students is significantly higher than students who, The level of learning burnout is significantly lower than that of non-party members. The above differences may be the result of the joint action of many factors, which will be elaborated and analyzed in the discussion section of this paper.

Table 4. Difference Test of College Students' Learning Burnout in Family Location and Political

\begin{tabular}{|c|c|c|c|c|c|}
\hline \multicolumn{6}{|c|}{ Status $(\mathrm{M} \pm \mathrm{SD})$} \\
\hline & & $\begin{array}{l}\text { In low } \\
\text { spirits }\end{array}$ & misconduct & $\begin{array}{l}\text { Low sense of } \\
\text { achievement }\end{array}$ & $\begin{array}{c}\text { Total learning } \\
\text { burnout }\end{array}$ \\
\hline \multirow{4}{*}{$\begin{array}{l}\text { family } \\
\text { home }\end{array}$} & $\begin{array}{c}\text { rural } \\
(98)\end{array}$ & $\begin{array}{c}23.65+1 \\
-6.28 \\
\end{array}$ & $\begin{array}{c}17.46+/- \\
4.53\end{array}$ & $15.70+/-3.87$ & $\begin{array}{c}56.82+/- \\
12.87\end{array}$ \\
\hline & $\begin{array}{c}\text { Cities and towns } \\
\text { (192) }\end{array}$ & $\begin{array}{c}21.44+1 \\
-6.67\end{array}$ & $\begin{array}{c}16.08+/- \\
4.79\end{array}$ & $15.23+/-4.10$ & $\begin{array}{c}52.76+/ \text { - } \\
13.71\end{array}$ \\
\hline & $t$ & 2.72 & 2.36 & 0.94 & 2.43 \\
\hline & sig & 0.00 & 0.02 & 0.35 & 0.02 \\
\hline \multirow{4}{*}{$\begin{array}{l}\text { Political } \\
\text { landscape }\end{array}$} & $\begin{array}{l}\text { The Chinese communist } \\
\text { party member } \\
(67)\end{array}$ & $\begin{array}{c}20.46+/ \\
-6.68 \\
\end{array}$ & $\begin{array}{c}15.49+/- \\
4.98\end{array}$ & $13.16+/-3.17$ & $\begin{array}{c}49.12+/- \\
12.67\end{array}$ \\
\hline & Non-CPC Members (223) & $\begin{array}{c}22.71+/ \\
-6.52 \\
\end{array}$ & $\begin{array}{c}16.86+/ \text { - } \\
4.63\end{array}$ & $16.06+/-4.02$ & $\begin{array}{c}55.64+/ \text { - } \\
13.47 \\
\end{array}$ \\
\hline & $t$ & 2.46 & 2.08 & 6.14 & 3.52 \\
\hline & sig & 0.01 & 0.04 & 0.00 & 0.00 \\
\hline
\end{tabular}

\subsubsection{Test of Variance}

Univariate analysis of variance was conducted to study the degree of college students' learning engagement and learning burnout. The significance probability of the total score variables in the homogeneity variance test is 0.76 , greater than 0.05 , which meets the homogeneity condition of oneway variance test, indicating that the following one-way variance test results are valid. The significance level of each dimension is lower than 0.05 , indicating that there are significant differences between the levels of learning engagement and learning burnout among different grades. Combined with the results of post-multiple comparison test, it is found that the level of learning engagement and learning burnout of college students ranked in the top $40 \%$ of grade are significantly higher than those in the bottom $60 \%$ of grade, and significantly lower than those in the bottom $60 \%$ of grade.

\subsection{Correlation Analysis among Variables}

The descriptive statistics and correlation analysis results of each variable are shown in Table 6 . The results show that learning engagement, academic Self-efficacy and learning burnout are significantly correlated. There is a significant positive correlation between learning engagement and academic Self-efficacy, a significant negative correlation between learning engagement and learning burnout, and a significant negative correlation between academic Self-efficacy and learning burnout. The results of correlation analysis showed that learning engagement, academic Self-efficacy and learning burnout were suitable for mediating effect analysis. 
Volume 3 (2021)

Table 5. Test of the Difference Between Learning Engagement and Learning Burnout in Academic Performance Ranking

\begin{tabular}{|c|c|c|c|c|c|c|}
\hline The dimension & options & $\begin{array}{c}\text { The } \\
\text { average }\end{array}$ & $\begin{array}{l}\text { The standard } \\
\text { deviation }\end{array}$ & $\mathrm{F}$ & significant & $\begin{array}{l}\text { Post hoc multiple } \\
\text { comparison }\end{array}$ \\
\hline \multirow{5}{*}{ motivation } & Bottom $20 \%$ & 27.31 & 8.03 & 9.25 & 0.00 & \multirow{5}{*}{$\begin{array}{l}5>1 \\
5>2 \\
5>3 \\
5>4\end{array}$} \\
\hline & Bottom $20 \% \sim 40 \%$ & 27.03 & 4.84 & & & \\
\hline & Grade $40 \% \sim 60 \%$ & 28.57 & 5.57 & & & \\
\hline & Top $20 \% \sim 40 \%$ & 30.27 & 5.95 & & & \\
\hline & The top $20 \%$, grade & 32.52 & 5.47 & & & \\
\hline \multirow{5}{*}{ energy } & Bottom 20\% & 22.69 & 8.20 & 9.79 & 0.00 & \multirow{15}{*}{$\begin{array}{l}4>1 \\
4>2 \\
5>1 \\
5>2 \\
5>3 \\
5>4\end{array}$} \\
\hline & Bottom $20 \% \sim 40 \%$ & 22.97 & 5.08 & & & \\
\hline & Grade $40 \% \sim 60 \%$ & 24.58 & 6.72 & & & \\
\hline & Top 20\% 40\% & 26.29 & 6.62 & & & \\
\hline & The top $20 \%$, grade & 29.12 & 6.13 & & & \\
\hline \multirow{5}{*}{ focus } & Bottom 20\% & 18.94 & 6.92 & 8.92 & 0.00 & \\
\hline & Bottom $20 \% \sim 40 \%$ & 20.24 & 4.14 & & & \\
\hline & Grade $40 \% \sim 60 \%$ & 21.52 & 5.00 & & & \\
\hline & Top 20\% 40\% & 22.51 & 5.43 & & & \\
\hline & The top 20\%, grade & 24.70 & 4.96 & & & \\
\hline \multirow{5}{*}{$\begin{array}{l}\text { The total } \\
\text { investment }\end{array}$} & Bottom 20\% & 68.94 & 22.50 & 10.46 & 0.00 & \\
\hline & Bottom $20 \% \sim 40 \%$ & 70.24 & 13.16 & & & \\
\hline & Grade $40 \% \sim 60 \%$ & 74.67 & 16.27 & & & \\
\hline & Top 20\% 40\% & 79.07 & 17.23 & & & \\
\hline & The top $20 \%$, grade & 86.34 & 15.33 & & & \\
\hline \multirow{5}{*}{ In low spirits } & Bottom 20\% & 27.81 & 8.64 & 20.07 & 0.00 & \multirow{10}{*}{$\begin{array}{l}1>3 \\
1>4 \\
1>5 \\
2>3 \\
2>4 \\
2>5 \\
3>4 \\
3>5 \\
4>5\end{array}$} \\
\hline & Bottom $20 \% \sim 40 \%$ & 27.18 & 5.58 & & & \\
\hline & Grade $40 \% \sim 60 \%$ & 24.26 & 5.34 & & & \\
\hline & Top $20 \% \sim 40 \%$ & 21.56 & 6.58 & & & \\
\hline & The top $20 \%$, grade & 18.90 & 6.61 & & & \\
\hline \multirow[t]{5}{*}{ Total burnout } & Bottom 20\% & 65.75 & 17.54 & 21.92 & 0.00 & \\
\hline & Bottom 20\% 40\% & 64.58 & 10.32 & & & \\
\hline & Grade $40 \% \sim 60 \%$ & 58.62 & 12.05 & & & \\
\hline & Top 20\% 40\% & 52.97 & 12.18 & & & \\
\hline & The top $20 \%$, grade & 47.03 & 11.13 & & & \\
\hline \multirow{10}{*}{$\begin{array}{l}\text { Low sense of } \\
\text { achievement }\end{array}$} & Bottom 20\% & 19.56 & 5.59 & 12.31 & 0.00 & \multirow{10}{*}{$\begin{array}{l}1>4 \\
1>5 \\
2>4 \\
2>5 \\
3>5 \\
4>5\end{array}$} \\
\hline & Bottom $20 \% \sim 40 \%$ & 19.68 & 3.64 & & & \\
\hline & Grade $40 \% \sim 60 \%$ & 17.65 & 4.50 & & & \\
\hline & Top 20\% 40\% & 16.29 & 4.25 & & & \\
\hline & The top 20\%, grade & 14.58 & 4.48 & & & \\
\hline & Bottom 20\% & 18.38 & 5.06 & 14.65 & 0.00 & \\
\hline & Bottom 20\% 40\% & 17.73 & 3.19 & & & \\
\hline & Grade $40 \% \sim 60 \%$ & 16.71 & 4.07 & & & \\
\hline & Top 20\% 40\% & 15.13 & 3.75 & & & \\
\hline & The top $20 \%$, grade & 13.55 & 3.28 & & & \\
\hline
\end{tabular}

Note: 1 represents the bottom $20 \%$ of grade, 2 represents the bottom $20 \% \sim 40 \%$ of grade, 3 represents $40 \%$ 60\% of grade, 4 represents the top $20 \% \sim 40 \%$ of grade, and 5 represents the top $20 \%$ of grade 
Table 6. Descriptive Statistics and Correlation Analysis of Study Variables

\begin{tabular}{|c|c|c|c|c|}
\hline Variable $(\mathrm{N}=290)$ & $M+/-S D$ & 1 & 2 & 3 \\
\hline 1 Learning engagement & $79.138+/-17.282$ & 1.000 & & \\
\hline 2. Academic Self-efficacy & $73.217+/-10.029$ & $0.604 * *$ & 1.000 & \\
\hline 3 Learning burnout & $54.131+/-13.548$ & $0.810 * *$ & $0.549 * *$ & 1.000 \\
\hline Note: $* *$ represents $\mathrm{P}<0.01$ & \multicolumn{3}{|l}{} \\
\hline
\end{tabular}

\subsection{Regression Analysis of College Students' Learning Engagement and Academic Self- efficacy on Learning Burnout}

To college students' learning, academic Self-efficacy and learning burnout of the results of correlation analysis and stepwise regression method is adopted for the variables in the learning burnout and regression analysis, the results (see table 7) show that the learning and academic Selfefficacy can predict effectively the negative learning burnout level, its contribution rate reached $66 \%$, the proportion of larger, It plays an important role in predicting the level of learning burnout.

Table 7. Progressive Regression Analysis of Learning Engagement and Academic Selfefficacy on Learning Burnout

\begin{tabular}{|c|c|c|c|c|c|}
\hline The dependent variable & Predictor variable & Adjusted R2 & Beta. & $\mathrm{F}$ & $t$ \\
\hline Learning burnout & Learning in & \multirow{2}{*}{0.660} & 0.591 & \multirow{2}{*}{$281.076^{* * *}$} & $17.509^{* * *}$ \\
\cline { 2 - 2 } & Academic Self-efficacy & & 0.127 & & \\
\hline
\end{tabular}

\subsection{The Mediating Effect of Academic Self-efficacy on Learning Engagement and Learning Burnout}

It can be seen from Table 6 that learning engagement, academic Self-efficacy and learning burnout are significantly correlated in pairs, which meets the premise of mediating effect test. This study constructs a model diagram of the mediating effects among the three (see Figure 1).

Table 8. Model Test of Mediating Effect of Academic Self-efficacy on the Relationship Between Learning Engagement and Learning Burnout (Standardized)

\begin{tabular}{|c|c|c|c|c|c|c|}
\hline \multirow[t]{2}{*}{ Predictor variable } & \multicolumn{2}{|c|}{$\begin{array}{c}\text { Model } 1 \\
\mathrm{Y}=0.635 \mathrm{X} \text { X }\end{array}$} & \multicolumn{2}{|c|}{$\begin{array}{c}\text { Model } 2 \\
\mathrm{M}=0.350 \mathrm{X} X\end{array}$} & \multicolumn{2}{|c|}{$\begin{array}{c}\text { Model 3 } \\
\mathrm{Y}=0.590 \text { X X 0.127 X M }\end{array}$} \\
\hline & Beta. & $\mathrm{t}$ & Beta. & $\mathrm{t}$ & Beta. & $\mathrm{t}$ \\
\hline Learning in & 0.635 & $23.458^{* * * *}$ & 0.350 & $12.849^{\text {*** }}$ & 0.590 & $17.509^{\text {**** }}$ \\
\hline Academic Self-efficacy & & & & & 0.127 & $2.178^{* * *}$ \\
\hline $\mathrm{R}^{2}$ & \multicolumn{2}{|c|}{0.656} & \multicolumn{2}{|c|}{0.027} & \multicolumn{2}{|c|}{0.662} \\
\hline
\end{tabular}

Note: Model 1 is independent variable learning engagement to predict dependent variable learning burnout; Model 2 is independent variable learning engagement to predict the mediating variable academic Self-efficacy. In model 3, the independent variable learning engagement and the mediating variable academic Self-efficacy jointly predicted learning burnout.

According to Model 1, the linear regression equation of learning engagement to learning burnout is $\mathrm{Y}=-0.635 \times \mathrm{X}$, and the regression coefficient $\mathrm{C}$ is significant. Therefore, learning engagement has a certain predictive effect on academic Self-efficacy. According to Model 2, the linear regression equation of learning engagement to academic Self-efficacy is $M=0.350 \times X$, and the regression coefficient a is significant. Therefore, learning engagement has a certain predictive effect on academic Self-efficacy. According to Model 3, with the addition of the mediating variable academic Selfefficacy, academic Self-efficacy also has a predictive effect on learning burnout, and the regression coefficient B is significant. In addition, learning engagement still has a predictive effect on learning burnout, so academic Self-efficacy plays a partial intermediary role in the relationship between 
learning engagement and learning burnout. Learning engagement and the mediating variable academic Self-efficacy jointly predicted the dependent variable learning burnout. The linear regression equation was $\mathrm{Y}=-0.590 \times \mathrm{x}-0.127 \times \mathrm{M}$, and the mediating effect rate was $7 \% \cdot \frac{a b}{c}$.
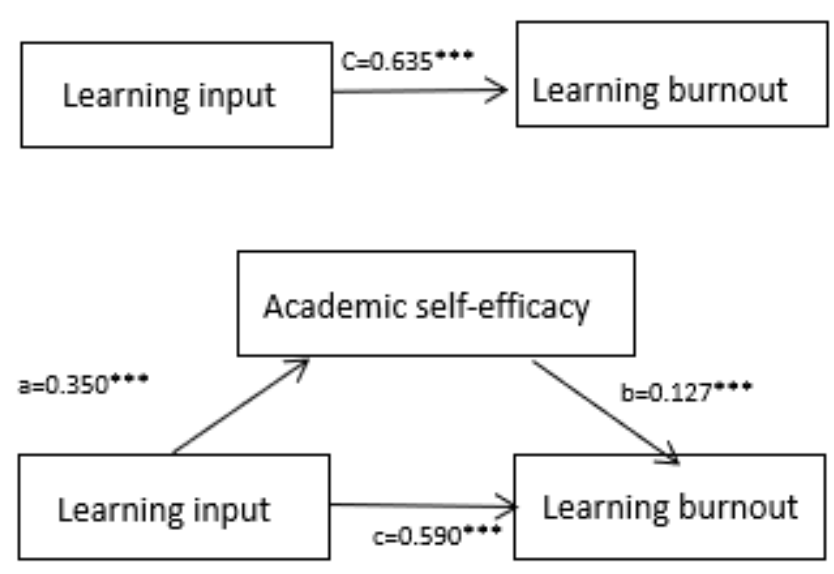

Fig 1. Mediating effect model diagram

\section{Discussion}

\subsection{The Status Quo of Learning Engagement and Learning Burnout}

This study shows that there are significant gender differences in the total score of learning engagement and the scores of energy and concentration. Boys score higher than girls, which is consistent with previous studies.[24]Analysis of the reason may be caused by the habitual cognition of male and female college students' social gender. Due to the difference of social gender, boys and girls are given different stereotypes in the society. People generally judge the success of boys by their career achievements and girls by their family management. The achievement motivation given to boys from childhood makes them better able to recognize the significance of learning, and thus more likely to maintain a lasting enthusiasm for learning and a higher degree of learning engagement. In terms of class positions, previous studies have found that class leadership has a positive predictive effect on learning engagement.[25]This is consistent with the results of this study. The scores of college students serving as class leaders in terms of learning engagement and sub-dimensions are significantly higher than those of non-class leaders. As class leaders, they need better ability of organization and coordination, communication and expression, which can subtly improve their learning ability.[25] Moreover, as a class leader, they are more likely to get more honors and awards, which will further stimulate their study.[24]So as to improve the degree of learning engagement. This study shows that there are significant regional differences in the scores of learning engagement and learning burnout. In contrast, college students from rural areas show a lower degree of learning engagement and a higher level of learning burnout. Relevant studies indicate that urban and rural areas represent different resource allocation. [25-27] In recent years, due to national attention and support, the rural education has a certain development, but overall is still insufficient, which leads to poor foundation of college students. The rural students and college students generally introverted personality, who are reluctant to speak in terms of learning, poor communication, do not dare to ask, in many cases, leading to blind learning, and learning difficulties,[28]As time goes by, the negative attitude towards learning is manifested by the decrease of learning engagement and the increase of learning burnout. Similarly, commitment and learning burnout of total dimensions and each dimension on the political landscape of $\mathrm{p}$ values are less than 0.05 , the scores of college student party members degree of learning in college students is significantly higher than non-party people, their learning burnout level was significantly lower than non-party people, college students will study at the core of college student party members' advanced nature,[28]Make university student party 
member pay more attention to his study situation, to study the investment degree is higher too. On the performance ranking, in different ranking interval of college students in learning and learning burnout scores have significant difference, the difference may exist because scores ranking on the ability of college students for their own, in the future, such as lack of confidence, enthusiasm for learning gradually faded, gradually reduce, the degree of learning into pessimistic psychology on the studies, The level of learning burnout increases gradually.

\subsection{The Relationship between Learning Engagement and Learning Burnout}

According to the correlation analysis results of this study, the learning investment of college students is significantly negatively correlated with learning burnout. The regression analysis results show that the learning investment of college students can significantly negatively predict learning burnout, which is consistent with the conclusions of previous researches.[4,8,9,16]It shows that if students keep a positive mental state for a long time and focus their attention on the solution of problems rather than the emergence of problems, the possibility of negative state can be effectively reduced and the level of learning burnout can be reduced. The reason may be that the students' learning motivation is strong, willing to take the initiative to learn, in the usual learning will take the initiative to avoid being late, leave early, truancy, such as bad learning behavior, so as to improve the possibility of get good learning effect, and get a sense of achievement, giving yourself positive psychology to allude, reduce the possibility of low mood appear; Having sufficient energy in the study, more intently involved in the study itself is a kind of positive psychological performance, in the process is not easy to produce negative emotions, high concentration often represents the learning efficiency, accomplish by students in the learning process is more, the achievement is higher, and not easily get learning burnout.

\subsection{The Mediating Effect of Academic Self-efficacy}

This study found that college students' academic Self-efficacy in the partial intermediary role between learning and learning burnout, the influence of the concrete paths for students to join actively in the learning process can help the progress of learning, to experience more of a sense of accomplishment, feeling has realized self value, strengthen academic Self-efficacy, thus forming a positive feedback, to further strengthen the investment in learning, They are also more interested in learning, so they are not prone to learning burnout.[7]In this study, the mediating effect rate is $7 \%$, which has a certain gap with the standard value of $20 \%$. It is speculated that learning engagement is a variable under the interaction between individuals and the environment, and will be affected by multiple internal and external influences of learners, indicating that the mechanism of learning engagement on learning burnout may be influenced by academic emotions $\frac{a b}{c}$ [1] Hope trait [4] Professional commitment $[5,8]$ And many other factors.

It is an innovation of this study to introduce academic Self-efficacy as a mediating variable into the influence mechanism of learning engagement on learning burnout, which makes up for the deficiency of current research to some extent.This study based on a study into three variables, academic Self-efficacy and learning burnout that learning the relationship between inputs and academic Self-efficacy in the prevention of learning burnout has a certain instruction value, both to improve college students' learning enthusiasm and enhance college students' academic Self-efficacy can effectively reduce the learning burnout level, This suggests that we can improve students' academic Self-efficacy and reduce their learning burnout through positive self-suggestion. [13] It has certain practical significance.

\section{Advice}

The above discussion enables us to clarify the difference between college students' learning engagement and learning burnout and the influence mechanism between them, as well as the mediating role of academic Self-efficacy between them. In order to alleviate the differences between 
different demographic variables and improve students' Self-efficacy, this study proposes suggestions from both organizational and individual levels.Among them, the organizational level includes the government, society and school, while the individual level refers to students themselves.

At the organizational level, the following suggestions are put forward: First, at the government level, the regional differences of students' learning engagement and learning burnout are related to the imbalance of educational resource allocation.[28] The government should take the legal protection of education rights and interests in weak areas and the effective satisfaction of development needs as the starting point of its own work, so as to balance the regional allocation of education resources and narrow the gap between urban and rural education levels. The second is the social level. For the regional differences among students, the society can take the rational allocation and optimal utilization of market resources as the foothold and give play to the role of competition in the allocation of educational resources. As for the gender differences shown by students, the society can break stereotypes and improve the inclusiveness of gender roles by strengthening the equal rights of gender roles in division of labor. Finally, schools should pay attention to students' psychological education and carry out elective courses such as pressure management. Secondly, schools can implement the tutorial system, and teachers should take the initiative to understand students' individual needs, such as postgraduate education, postgraduate entrance examination, and public entrance examination, so as to help students achieve their goals without delaying their professional learning. In a word, alleviating the differences among students in gender, region, class position and political status requires the joint efforts of the government, society and schools.

At the level of students, the following suggestions are put forward: First, change the cognition of difficulties and change the response to difficulties, so that the same difficulties can be more stressful psychologically and energetically, so as to avoid learning burnout caused by learning pressure to a certain extent; Secondly, by cultivating learning interest, balancing learning motivation, and frequent review to promote the investment in learning, so as to better complete learning tasks, so as to enhance the sense of academic Self-efficacy, effectively reduce the level of learning burnout; Third, actively face the negative emotions in the learning process, take the initiative to attend the relevant courses and lectures offered by the school, learn the skills of coping with pressure, venting emotions and managing time, and reduce the level of learning burnout.

\section{Conclusion}

Learning burnout is universal. How to reduce learning burnout has always been a practical problem faced by colleges and universities. It is an innovative approach to enhance Self-efficacy and reduce learning burnout by improving the degree of learning engagement. This study will provide a strong theoretical basis for the teaching reform of colleges and universities. There are also some deficiencies in this study. On the one hand, this study mainly measures relevant variables through scales. Although scales are widely used to measure the learning status of college students as a self-reporting method and are considered to have good reliability and validity, However, homology error exists to some extent, which may affect the objectivity of the study.Future research can consider using objective indicators and more diversified investigation methods to make the research results more scientific and rigorous.On the other hand, the discussion of individual variables is not deep enough in this study.Future studies may include more in-depth variables such as ethnic differences and values differences for analysis.

\section{References}

[1] Zhao, S. Y, Chen, Z. J. The mediating role of academic Self-efficacy between college students' positive academic emotion and achievement goals[J/OL]. China Journal of Health Psychology:1-8[2021-10-31]. http:// kns.cnki.net /kcms/detail/11.5257.R.20210824.1308.017.html.

[2] Wilmar B. Schaufeli. Burnout and Engagement in University Students[J]. Journal of Cross-Cultural Tended, 2002(5). 
Volume 3 (2021)

[3] Gary R. Pike, et al. An Investigation of the Contingent Relationships Between Learning Research in Higher Education,2011,52(3).

[4] Zhang, L. D., et al. Freshmen's Learning Burnout and Learning Engagement: Regulatory Effect of Hope trait Empirical Study on Medical Freshmen from Peking University[J]. Education Research Monthly, 2016 (11):89-95.

[5] Lian R., et al. Relationship between Professional Commitment and Learning Burnout of Undergraduates and Scales Developing [J]. Acta Psychological Sinica,2005 (05):632-636.

[6] Wu Y., et al. the Development of Adolescent Student Burnout Inventory[J]. Chinese journal of Clinical Psychology, 2010,18(02):152-154.

[7] Shen L.Y.,et al.Studying on the influences of learning injection and core self-evaluation on learning burnout of rural-oriented medical students.[J].The Chinese Health Service Management,2016,33(07):547549.

[8] Duan L. S. et al., The Relationship between Professional Commitment, Learning Burnout and Learning Engagement of undergraduates. [J]. China Journal of Health Psychology,2008(04):407-409.

[9] Zhang Z., et al. The Relationship between Undergraduates' Coping Efficacy, Learning Burnout and Learning Engagement. China Journal of Health Psychology,2009,17(03):282-284.

[10] Bi J.,et al.An Analysis of the Relationship Between the Advanced Nature of College StudentsParty Members and Their Learning[J].The Party Building and Ideological Education in Schools,2012(16):1719.

[11] Albert B. Efficacy: Toward a Unifying Theory of Behavioral Change. [J]. Psychological Review, 1977, 84 (2).

[12] Amy L., et al. Engagement as Flourishing: The Contribution of Positive Emotions and Coping to Adolescents' Engagement at School and With Learning[J]. John Wiley\&Sons,Ltd,2008,(5).

[13] Else Ouweneel., et al. Flourishing Students: A Longitudinal Study on Positive Emotions, Personal Resources, Journal of Positive Psychology,2011,6(2).

[14] Wang X.M., et al. the Research on the Relationship Among Academic Self-efficacy, Self-esteem and Learning Burnout of the University Students[J]. Journal of Northeast Normal University (Philosophy and Social Sciences), 2012(01):192-196.

[15] Zhu X. B., et al. A Structural Equation Modeling of Perceived Academic Self-efficacy, Learning Stress, and Learning Burnout of High School Students[J]. Chinese Journal of Clinical Psychology, 2009, 17 (05): 626-628+543.

[16] Li Z., et al. The Relationship Between Professional Commitment, Learning Burnout and Academic Selfefficacy Among Undergraduate Nursing Students[J]. Chinese Journal of Behavioral Medicine and Brain Science, 2011(05):453-455.

[17] Wang J.N., et al. The influence of Parents-children Communication, Companion relationship and Teacher-student relationship on the Learning Achievement of Junior high school students [J]. Psychological Science, 2009, 32(06):1439-1441.

[18] Marion Donna., et al. Maternal Affection Moderates Friend Influence on Schoolwork Engagement. [J]. Developmental Psychology,2014,50(3).

[19] Shi L. S., et al. Social Economic Status and Study Engagement: The Mediating Effects of Academic Selfefficacy among Junior High School Students[J]. Psychological Development and Education, 2013, 29 (01): 71-78.

[20] Baron Reuben M, Kenny David A. Mediator Variable Distinction in Social Psychological Research: Conceptual, Strategic, and Statistical Considerations. [J]. Journal of Personality and Social Psychology, 1986, 51(6):Conceptual, Strategic, and Statistical Considerations.

[21] Li X. Y., et al. A Revise of the UWES-S of Chinese College Samples. [J]. Psychological Research, 2010, 3 (01):84-88.

[22] Liang Y.S. Study on Achievement Goals, Attribution Styles and Academic Self-efficacy of Collage Students [D]. School of Psychology, Central China Normal University,2000.

[23] Lian R.,et al.Relationship between Professional Commitment and Learning Burnout of Undergraduates and Scales Developing[J].Acta Psychological Sinica,2005,37(5):632-636. 
Volume 3 (2021)

[24] Guo J.P., et al. The Mechanism Affecting College Students'Learning Engagement and a Model:Based on a Survey of Student Learning in 311 Undergraduate Colleges and Universities[J].Educational Research, 201, 42(08):104-115.

[25] Quan X.J., et al. A Comparative Study of University Students' Performance in Urban and Rural Areas China Youth Study [J]. China Youth Study,2017(03):88-93+109.

[26] Fan Y.K., et al. A Research Report on Balanced Development of Rural and Urban Education Resource in China [J].Educational Research,2014,35(11):32-44+83.

[27] Wei J., et al. Research on Transformation of Weak Schools Policy in China since the Reform and Opening-up--From the Historical Systems Perspective[J]. Contemporary Education Sciences, 2020 (12): 80-88.

[28] Luo J., et al. the Mediating Effect of Gender on the Relationship Between College Students' Learning Adjustment and Burnout [J]. Chinese Journal of Special Education (Monthly),2013(06):69-73.

[29] Shen D., et al. Analysis on the healthy development path of learning burnout college students in perspective of positive psychology [J]. Chinese Journal of Health Education,2019,35(08):765-767. 